\title{
INVESTIGATION ON QUALITY PROPERTIES OF TRADITIONAL BULK BREAD COVERED WITH PROBIOTICS AND SOYBEAN OIL EDIBLE COATING
}

\author{
R. Amiri Qandashtani ${ }^{\mathrm{a}}$, E. Ataye Salehi ${ }^{\mathrm{a}}$, A. Mohamadi Sani ${ }^{\mathrm{a}}, \mathrm{M}$. Mehraban \\ SANGATASH ${ }^{\mathrm{b}}$ and O. SAFARI ${ }^{\mathrm{c}}$

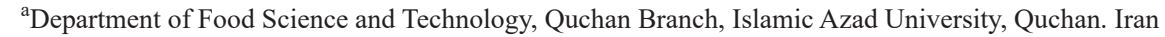 \\ ${ }^{b}$ Food Quality and Safety Research Department, Food Science and Technology Research Institute, ACECR \\ Khorasan Razavi Branch, Mashhad. Iran \\ ${ }^{\mathrm{c}}$ Department of Fishery, Faculty of Natural Resources and Environment, Ferdowsi University of Mashhad, \\ Mashhad. Iran
}

(Received: 3 August 2019; accepted: 14 December 2019)

\begin{abstract}
Probiotic food products are available at the supermarket commercially, but probiotic bakery products are much less in evidence. In the present study, methyl cellulose $(2 \%)$, whey protein concentrate $(2 \%)$, corn starch $(1 \%)$, and soybean oil at 2, 4, and $6 \%$ were used for coating layer on the bulked bread surface, and then the quality properties were studied. The results showed that Lactobacillus rhamnosus GG, as probiotic component of the coating, immobilized in corn starch, whey protein, and methyl cellulose films had enhanced viability throughout shelf-life. The probiotics remained viable for 4 days, maintaining high viable cell number levels. Adding soybean oil at $6 \%$ concentration enhanced texture, sensory properties, and image index during storage.
\end{abstract}

Keywords: coating, corn starch, functional food, Lactobacillus rhamnosus GG, methyl cellulose, whey protein concentrate

Over the past decade, production of functional foods has increased, due to their positive effect on both health and international trade. Functional foods were number one in the field of food biotechnology with increasing production. Changing trends in population demography, improved education, consumer affluence, life expectancy, and also improved health care resulted in emerging diet trends and health conscious clientele (Dillard \& GERMAN, 2000; YANG, 2008).

Functional food ingredients like probiotics and prebiotics are found in diverse products like fermented milk, yoghurt, baby foods, sports drinks, sugar-free confectionary, and chewing gum (KHAN \& ANSARI, 2007). Probiotic food products have been available at the supermarket for the last decade commercially, like yogurt, cheese, milk, ice cream, infant formulations, juices, and beverages, but probiotic bakery products are much less evident in the food industry.

Bread is a fundamental ingredient for daily consumption all over the world. Increasing consumer awareness about the healthy bakery products, for example breads with reduced fat, salt, and sugar in formulation, bread enriched with vitamins and minerals, has led to better health aspects of bread (BELz et al., 2011; BigLIARDI \& GALATI, 2013). A method for conveying probiotics into breads is by using edible coatings (ALTAMIRANO-ForTOUL et al., 2012a,b). In

\footnotetext{
* To whom correspondence should be addressed.

Phone: +989151595817; e-mail: eatayesalehi@yahoo.com
} 
the present study, soybean was added to the probiotic coating composition and was also used for covering traditional bulk bread. This survey investigated the effect of probiotic coating on the traditional bulk bread quality.

\section{Materials and methods}

Probiotic strain of $L$. rhamnosus GG was purchased as freeze-dried culture from TakGene (Tehran, Iran), and kept at $-80^{\circ} \mathrm{C}$ until use. Methyl cellulose (MC, medium viscosity, 27.5$32 \%$ methoxyl content, Fluka), corn starch (27\% amylose, Sigma), and whey protein concentrate (35.1\% protein, Lactofoood, France) were supplied. Soybean oil (Ladan Co. Behshahr, Iran) was purchased from local market.

\subsection{Stock culture preparation of L. rhamnosus $G G$}

Probiotic strain L. rhamnosus GG was maintained frozen at $-80{ }^{\circ} \mathrm{C}$. Cultures were grown in MRS broth at $37^{\circ} \mathrm{C}$ for 48 hours. They were transferred to $50 \mathrm{ml}$ sterile tubes and centrifuged at $4000 \mathrm{~g}$ for 10 minutes. Supernatant liquid was discarded and the harvested bacterial cells were washed twice with phosphate-buffered saline (pH 7.0). (LóPEZ De LACEY et al., 2012)

\subsection{Formulation of emulsified probiotic films}

As described by DASHIPOUR and co-workers (2015), three different coatings were prepared (Table 1). The coating-forming solutions were obtained by dispersion of MC, corn starch, and whey protein concentrate (WPC) in concentrations determined in a previous study (Yoo \& KROCHTA, 2012) in $100 \mathrm{ml}$ distilled water at $70{ }^{\circ} \mathrm{C}$. To ensure uniform dispersion, solution was mixed well using magnetic stirrer at 500 r.p.m. for $40 \mathrm{~min}$. Then, soybean oil was added to the solution at 3 concentrations $(2,4,6 \%)$ and stirred at $70{ }^{\circ} \mathrm{C}$ for 20 minutes. Solution was heated to $80{ }^{\circ} \mathrm{C}$ for $10 \mathrm{~min}$ in order to kill potential pathogens. Air bubbles were removed from the solution by vacuum oven (JeioTech, Model OV-12, Korea). When the solution temperature was cooled down to $37^{\circ} \mathrm{C}, \mathrm{L}$. rhamnosus with a final concentration of $10^{9}$ $\mathrm{CFU} \mathrm{ml}{ }^{-1}$ was added to the coating-forming solutions.

Table 1. Composition of probiotic coatings applied onto the bread surface

\begin{tabular}{ll}
\hline Sample & Coating composition \\
\hline S1 & $1 \%$ Corn starch, $2 \%$ MC, $2 \% \mathrm{WPC}$ \\
& $2 \%$ Soybean oil \\
& $1 \%$ Probiotic cell \\
S2 & $1 \%$ Corn starch, $2 \%$ MC, $2 \% \mathrm{WPC}$ \\
& $4 \%$ Soybean oil \\
S3 & $1 \%$ Probiotic cell \\
& $1 \%$ Corn starch, $2 \%$ MC, $2 \% \mathrm{WPC}$ \\
& $6 \%$ Soybean oil \\
\hline
\end{tabular}

S1, S2, S3: Samples 1, 2, and 3 


\subsection{Bread preparation}

The formula used for bulk bread consisted of flour (65\%), water (32.5\%), lyophilized baker's yeast $(0.6 \%)$, sucrose $(0.6 \%)$, salt $(0.6 \%)$, and sunflower oil $(0.6 \%)$. First powder materials were mixed with a spiral mixer (Escher, Italy), then the water was added, and the mixing continued until uniform dough was obtained. The dough was split into samples of $150 \mathrm{~g}$, shaped, placed in baking trays, and fermented at $45^{\circ} \mathrm{C}$ and $85 \%$ moisture for 2 hours. Then, the samples were baked in oven at $180^{\circ} \mathrm{C}$ for 15 minutes (similarly to the method of MALEKI et al., 2014). Breads were cooled to $60^{\circ} \mathrm{C}$. Then, the probiotic coating-forming solution was distributed evenly by brushing on the crust of the bread loaves. They were dried at $60{ }^{\circ} \mathrm{C}$ for 5 min rapidly, then the bread samples were cooled to room temperature $\left(25^{\circ} \mathrm{C}\right)$, and packaged in polyethylene bags. All bread samples were stored at controlled temperature of $25^{\circ} \mathrm{C}$ with $55 \%$ RH. Bread samples were weighed before and after coating in order to be able to calculate the initial total viable count of L. rhamnosus GG on bread crust.

\subsection{Bread crust's colour}

The colour of the bread crust samples was assessed by using a Hunter lab colorimeter (Reston, USA). The CIELab colour scale was used in order to calculate the L* (black to white), $\mathrm{a}^{*}$ (red to green), and $\mathrm{b}^{*}$ (yellow to blue) parameters. The total colour difference $\Delta \mathrm{E}^{*}$ between the control sample (uncoated bread crust) and each individual bread crust was calculated by equation

$$
\Delta E^{*}=\sqrt{\left(\Delta L^{*}\right)^{2}+\left(\Delta a^{*}\right)^{2}+\left(\Delta b^{*}\right)^{2}}
$$

where: $\Delta \mathrm{L}^{*}, \Delta \mathrm{a}^{*}, \Delta \mathrm{b}^{*}$ are the brightness, redness, and yellowness intensity differences from the control sample.

\subsection{Mechanical characterization}

The changes in the texture of bulked bread were calculated by compression test using the CNS Farnell Device (TA.XT Stable Micro System, UK) connected to a computer, and by using the software Texture Probe. The sample was placed on a perforated surface under probe in order to perform the compaction test. The hardness was acquired by calculating the required force for bread perforation. The probe had a speed of $30 \mathrm{~mm} \mathrm{~min}{ }^{-1}$ and the test started with $0.05 \mathrm{~N}$ (PourfarZAD et al., 2009).

\subsection{Morphological characterization of bread crust}

Film samples were freezed in liquid nitrogen, and cryo-fractured for film cross-section evaluation with Scanning electron microscopy (SEM) (Cambridge Scan-360). Samples were fixed in a sample holder and also coated with gold particles. Micrographs were arranged by using an accelerating voltage of $5 \mathrm{kV}$.

\subsection{Enumeration of the bacteria}

The method described by SouKouLis and co-workers (2017) was adopted for the recovery of L. rhamnosus GG from the bread crust sample. According to this method, $1 \mathrm{~g}$ of bread crust samples were transferred to $9 \mathrm{ml}$ of sterile PBS and dissolved under constant agitation in an orbital incubator at $37{ }^{\circ} \mathrm{C}$ for $1 \mathrm{~h}$. The resulting solutions were subjected to serial dilution using phosphate-buffered saline. Each dilution was pour plated on MRS (MRS Agar, Oxoid 
Ltd., Basingstoke, UK), and the plates were stored at $37{ }^{\circ} \mathrm{C}$ for $72 \mathrm{~h}$ under anaerobic conditions. Enumeration of the bacteria was performed in triplicate following the standard plating methodology (CHAmpagne et al., 2011) and the total counts of the viable bacteria were expressed as log colony forming units per gram $\left(\log C F U g^{-1}\right)$. The survival rate of the bacteria throughout the film forming solution drying process was calculated according to the following equation:

$$
\% \text { viability }=100 \times \frac{N}{N_{0}}
$$

where: $N O$ and $N$ represent the number of viable bacteria prior and after the implemented drying process (ANANTA et al., 2005).

\subsection{Sensory evaluation}

The sensory evaluation of the bulked bread coated probiotic film was done by 10 trained panellists (from the faculty research centre, by triangle test) with the use of a hedonic scale of five points for overall acceptability (HEJRANI et al., 2017).

\subsection{Statistical analysis}

The data were analysed by using SPSS (SPSS, Chicago IL, USA) version 17 with 3 replications ( 3 sample one measurement) at 3 h, 2 days, and 4 days. Also the Duncan test was used in order to determine significant differences between samples. A P-value of less than 0.05 was considered significant.

\section{Results and discussion}

\subsection{Viability of probiotics in films during storage}

Figure 1 shows the probiotic strain viability and stability in S1, S2, and S3 films during storage ( 3 h, 2 and 4 days). Viability of L. rhamnosus GG well correlated with storage temperature $(\mathrm{P}<0.05)$. The result demonstrated that probiotics' viability decreased during storage, although by increasing the concentration of soybean oil, probiotic survival increased, so the highest probiotic viability was observed at the concentration of $6 \%$ of soybean oil. The obtained bacterial load of $5.6 \times 10^{7}$ to $4.6 \times 10^{7} \mathrm{CFU} \mathrm{g}{ }^{-1}$ met the essential range $\left(10^{6}-10^{7}\right)$ to obtain probiotic consumption benefits (TRIPATHI \& GIRI, 2014). PRASAD and co-workers (2003) have reported that reduction of water activity in the film can affect the viability of probiotics. In our study, soybean oil was added to the MC-corn starch-WPC films, and the results indicated that increasing the concentration of soybean oil would increase the probiotics' survival. Soybean oil helps to maintain freshness and moisture content of the film, which helps probiotics to survive.

NAG and co-workers (2011) said that temperatures near $0{ }^{\circ} \mathrm{C}$ improve cell viability. Moreover, addition of whey protein and glycerol to the film solution protects the viability of probiotic cells (TRIPATHI \& GIRI, 2014).

QUEZADA-GALLO (2009) reported that using starch-based coating applied onto white bread and doughnuts controlled additives liberation to the product, as a function of its water activity, increasing probiotic cells viability. 


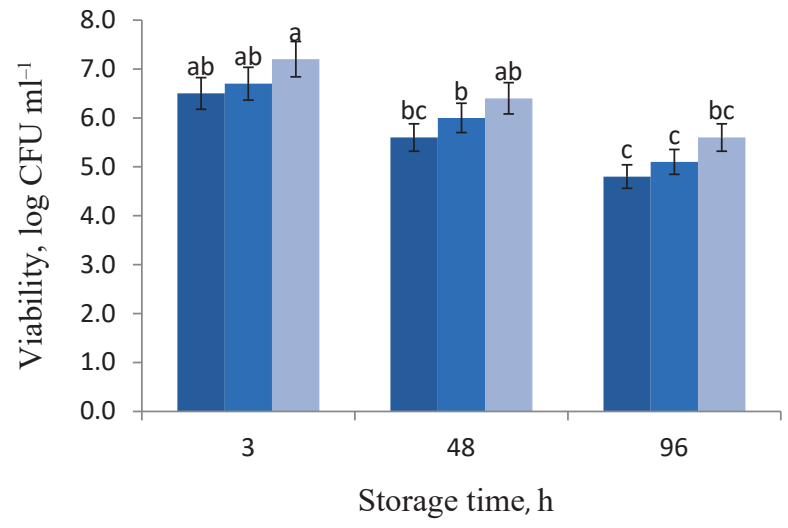

Fig. 1. Viability of L. rhamnosus GG in probiotic bread crust (based on corn starch, whey protein, MC, and three concentrations of soybean oil) during storage at temperature of $25^{\circ} \mathrm{C}$. All measurements are expressed as means $\pm \mathrm{SD}$ of three independent experiments. The different letters above the bars indicate significant differences at $\mathrm{P}<0.05$ level between treatments.

$$
\text { ㄸ: } \mathrm{S} 1 ; \mathrm{m:} 2 \text {; } 匚: \mathrm{S} 3
$$

\subsection{Image analysis}

Colour and transparency of the films are the most important visual aspects (PEREIRA et al., 2016). Bread crust colour was also affected by treatments with probiotic coatings. All films presented high brightness values ( $\mathrm{L}^{*}$ 90.88), showing that they are light-colour. The results are in agreement with findings of RHIM and co-workers (1998), who attained that the values of L* improved with probiotics films. BRINDLE and KROCHTA (2008) also obtained light, translucent films with glycerol, whey protein isolate, and hydroxypropylmethylcellulose.

All samples prepared with soybean oil maintained stable values of lightness ( $\left.\mathrm{L}^{*}\right)$, redness $\left(\mathrm{a}^{*}\right)$, and yellowness $\left(\mathrm{b}^{*}\right)$ throughout the storage period, but increasing soya oil concentration increased the image index $\left(\mathrm{L}^{*}, \mathrm{a}^{*}\right.$, and $\left.\mathrm{b}^{*}\right)$, as shown in Figure 2 as $\Delta \mathrm{E}$. The bread with treatment S3 had the highest lightness $\left(\mathrm{L}^{*}\right)$, and $\mathrm{a}^{*}$. Adding soybean oil to the films might affect light passing through the film, possibly due to increased light dispersion.

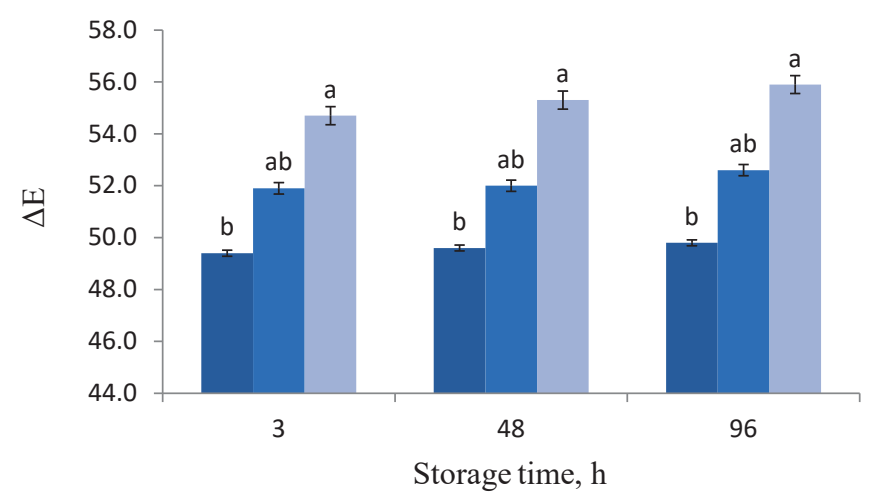

Fig . 2. $\Delta \mathrm{E}$ of probiotic bread crust (based on corn starch, whey protein, $\mathrm{MC}$, and three concentrations of soybean oil) during storage at temperature of $25^{\circ} \mathrm{C}$. All measurements are expressed as means $\pm \mathrm{SD}$ of three independent experiments. The different letters above the bars indicate significant differences at $\mathrm{P}<0.05$ level between treatments.

$$
\text { ㅁ: } \mathrm{S} 1 ; \mathrm{a}: \mathrm{S} 2 ; \mathrm{:}: \mathrm{S} 3
$$


GHANBARZADEH and co-workers (2010) reported enhanced optical properties and reduction in yellowness by adding carboxymethyl cellulose (CMC) to starch films.

Treatment S1 did not have any effect on the $\mathrm{a}^{*}$ parameter of the crust, but addition of soybean oil in treatment S2 and S3 led to an increase in this parameter. The presence of soybean oil yielded the lowest $b^{*}$ values of the crust.

\subsection{Texture analysis}

The probiotic coatings applied on the bulk bread surface caused remarkable changes in bread hardness (Fig. 3). The force needed for crust fracture considerably $(\mathrm{P}<0.05)$ decreased with soybean oil coatings. Treatment S3 (6\%) resulted in the lowest fracture force at storage time 0 and also after 4 days of storage. This phenomenon is explained by the soybean emulsion effect, which improves molecular mobility and its smaller molecules increase spacing and free volume in polymer chains (RouHI et al., 2017).

EBRAHIMI and co-workers (2018) reported that soybean oil was used in bacteriumcoating film to protect the bulk bread tissue. Although the textural properties of bread with probiotic coatings were improved, the failure force increased throughout the storage time (Fig. 3). The crust of the bread with low concentration of soybean oil revealed an increase in failure force as a result of moisture migration from the crumb to the crust. Bread with treatment S6 presented the lowest value of hardness both after $3 \mathrm{~h}$ and $96 \mathrm{~h}$ of storage, consequently coating S3 showed a small hardness increase during storage. Coating bulked bread with soybean oil modified hardness due to adding the new layers, which decreased the failure force in the fresh bread, but they did not considerably improve the trend during bread storage.

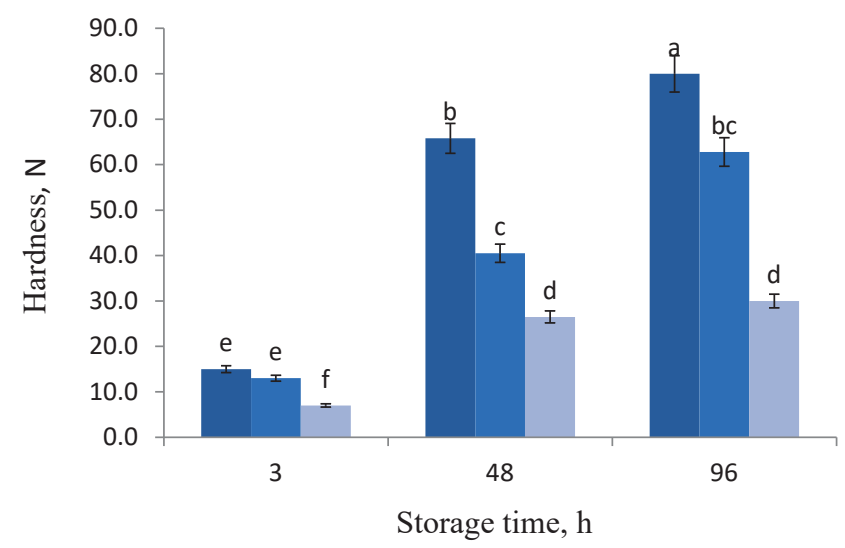

Fig. 3. Hardness of probiotic bread crust (based on corn starch, whey protein, MC, and three concentrations of soybean oil) during storage at temperature of $25^{\circ} \mathrm{C}$. All measurements are expressed as means $\pm \mathrm{SD}$ of three independent experiments. The different letters above the bars indicate significant differences at $\mathrm{P}<0.05$ level between treatments.

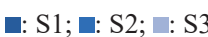




\subsection{Scanning electron microscopy (SEM)}

Incorporating the probiotic strain into the film did not obviously alter the film's structural conformation (Figs 4, 5, 6). The SEM results indicated that the structure of probiotic film based on corn starch, whey protein, and MC was homogeneous, uniform, and compact with no micro pores. However, probiotic films showed a higher number of holes after 4 days. Different levels of soybean oil did not result in detectable changes in the probiotic film's microstructure. In all cases, 3 hours after baking, the films retained their structure, having uniform and reticular characteristics. Coating S3, 3 hours after baking, showed a moderately regular surface and cohesive layer (Fig. 4), but during storage a slightly fragmented and opaque layer was observed (Figs 5, 6). Less compact structures and large cavities within the matrix were observed with the addition of soybean oil (Fig. 6). Aggregation was perhaps more difficult for oil formulation, due to the higher surface tension of liquid droplets (BRAVIN et al., 2006).

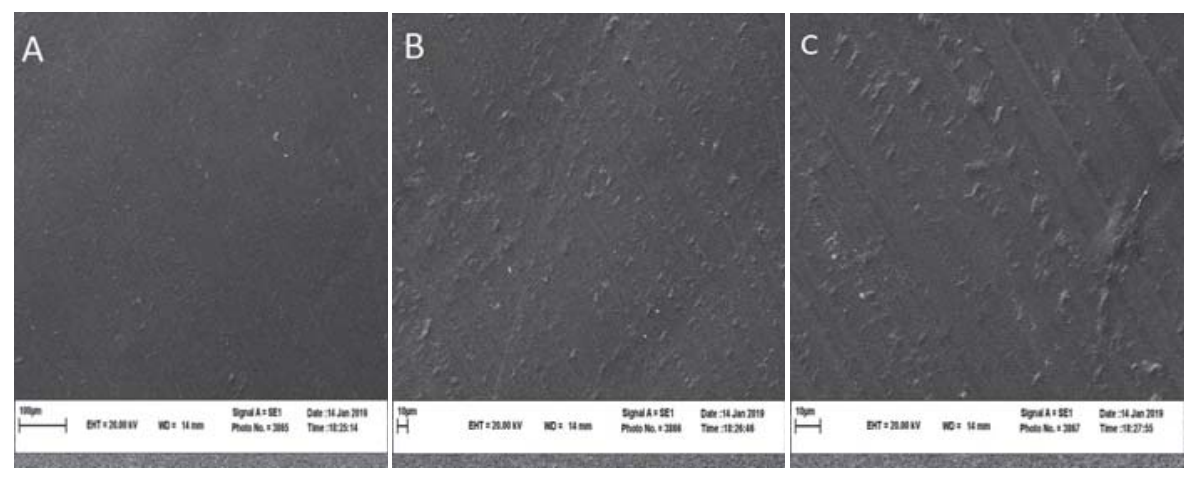

Fig. 4. Cross-section of the probiotic bread crust $3 \mathrm{~h}$ after baking using Scanning Electron Microscopy (A: S1, B: S2, C: S3)

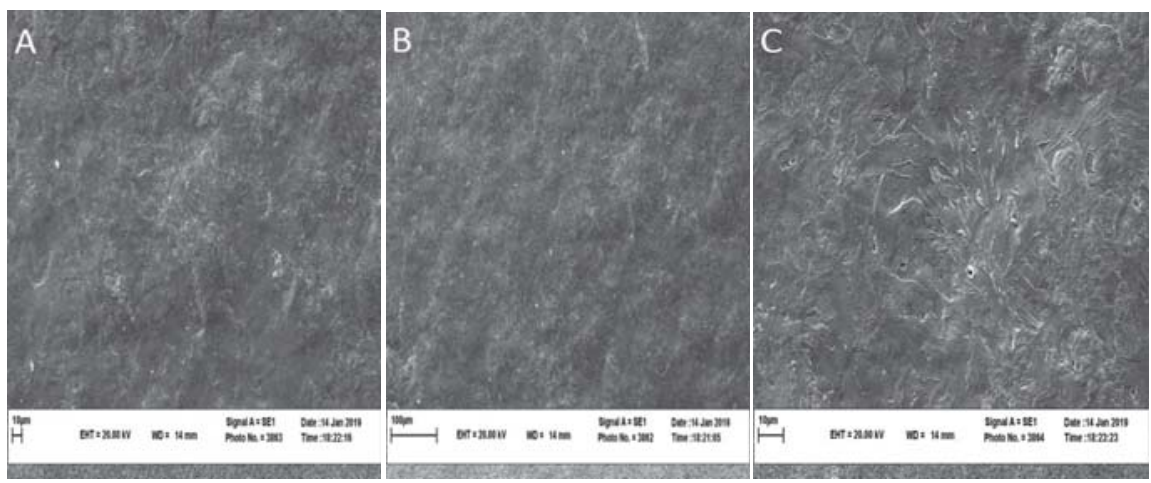

Fig. 5. Cross-section of the probiotic bread crust 2 days after baking using Scanning Electron Microscopy (A: S1, B: S2, C: S3) 


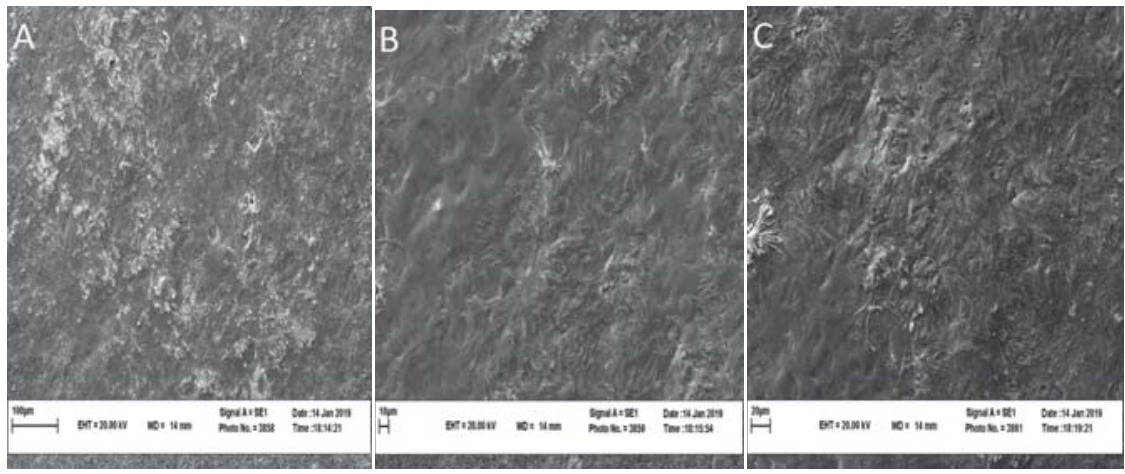

Fig. 6. Cross-section of the probiotic bread crust 4 days after baking using Scanning Electron Microscopy (A: S1, B: S2, C: S3)

\subsection{Sensory analysis}

The overall acceptability scores obtained for the coated bulked bread with different levels of soybean oil 3 hours after baking did not present major differences $(\mathrm{P}>0.05)$. By increasing the soybean oil level to $6 \%$, the sensory properties score increased, and this high acceptability remained even after 2 days of storage, The acceptance score of the bulk bread coated with S1, S2, and S3 films was considerably lower $(\mathrm{P}<0.05)$ after 4 days of storage $(4.5 \pm 0.6$ and $1.9 \pm 0.4$, respectively) (Fig. 7). The results displayed in Figure 7 demonstrate as a whole that coating the bulked bread with S1, S2, and S3 films does not alter their excellent sensory attributes.

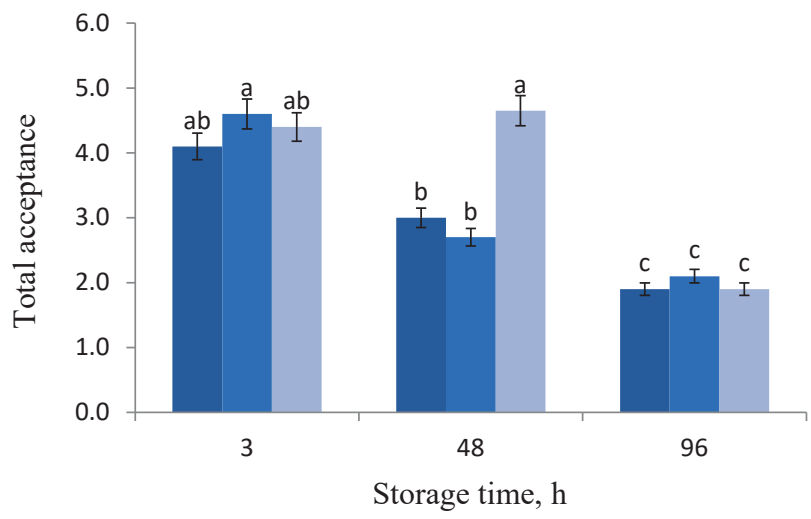

Fig. 7. Total acceptance of bulked bread coated with probiotic coating (based on corn starch, whey protein, MC, and three concentrations of soybean oil) during storage at temperature of $25^{\circ} \mathrm{C}$. All measurements are expressed as means $\pm \mathrm{SD}$ of three independent experiments. The different letters above the bars indicate significant differences at $\mathrm{P}<0.05$ level between treatments. 


\section{Conclusions}

According to the findings, we conclude that S1, S2, and S3 films could act as a suitable matrix in order to incorporate probiotic L. rhamnosus GG and improve their viability throughout shelf-life. The probiotics remained viable during 4 days of storage maintaining high viable cell number levels. It is also worth mentioning that no structural changes in the film were observed during the study period, when using soybean oil at $6 \%$ concentration provided softer texture and with no significant difference at image index. Consequently, edible films like of corn starch, whey protein, $\mathrm{MC}$, and soybean oil could be good carriers for L. rhamnosus GG immobilized in the film used for bulked bread.

\section{References}

Altamirano-Fortoul, R., Le-Bail, A., Chevallier, S. \& Rosell, C. (2012a): Effect of the amount of steam during baking on bread crust features and water diffusion. J. Food Eng., 108, 128-134.

Altamirano-Fortoul, R., Moreno-Terrazas, R., Quezada-Gallo, A. \& Rosell, C. (2012b): Viability of some probiotic coatings in bread and its effect on the crust mechanical properties. Food Hydrocolloid, 29, $166-174$.

AnAnta, E., Volkert, M. \& KNORR, D. (2005): Cellular injuries and storage stability of spray-dried Lactobacillus rhamnosus GG. Int. Dairy J., 15, 399-409.

Belz, M., Ryan L. \& Arendt, E. (2011): The impact of salt reduction in bread: a review. Crit. Rev. Food Sci. Nutr., 52, 514-524.

Bigliardi, B. \& Galati, F. (2013): Innovation trends in the food industry: the case of functional foods. Trends Food Sci. Tech., 31, 118-129.

Bravin, B., Peressini, D. \& Sensidoni, A. (2006): Development and application of polysaccharide-lipid edible coating to extend shelf-life of dry bakery products. J. Food Eng., 76, 280-290.

Brindle, L. \& Krochta, J. (2008): Physical properties of whey protein-hydroxy propyl methylcellulose blend edible films. J. Food Sci., 73, 446-454.

Champagne, C.P., Ross, R.P., Saarela, M., Hansen, K.F. \& Charalampopoulos, D. (2011): Recommendations for the viability assessment of probiotics as concentrated cultures and in food matrices. Int. J. Food Microbiol., 149, 185-193.

Dashipour, A., Razavilar, V., Hosseini, H., Shojaee-Aliabadi, S., German, J. \& Ghanati, K. (2015): Antioxidant and antimicrobial carboxymethyl cellulose films containing Zataria multiflora essential oil. Int. J. Biol. Macromol., 72, 606-613.

Dillard, C. \& German, J. (2000): Phytochemicals: Nutraceuticals and human health. J. Sci. Food Agr., 80, 1744 1756.

Ebrahimi, B., Mohammadi, R., Rouhi, M., Mortazavian, A., Shojaee-Aliabadi, S. \& Koushki, M. (2018): Survival of probiotic bacteria in carboxymethyl cellulose-based edible film and assessment of quality parameters. LWT-Food Sci. Technol., 87, 54-60.

Ghanbarzadeh, B., Almasi, H. \& Entezami, A. (2010): Physical properties of edible modified starch/carboxymethyl cellulose films. Innov. Food Sci. Emerg., 11, 697-702.

Hejrani, T., Sheikholeslami, Z., Mortazavi, A. \& Ghiyafe Davoodi, M. (2017): The properties of part baked frozen bread with guar and xanthan gums. Food Hydrocolloid, 71, 252-257.

Hosseini, S.F., Rezaei, M., Zandi, M. \& Ghavi, F.F. (2013): Preparation and functional properties of fish gelatine chitosan blend edible films. Food Chem., 136, 1490-1495.

Khan, S.H. \& ANSARI, F.A. (2007): Probiotics - The friendly bacteria with market potential in global market. Pak. J. Pharm. Sci., 20, 71-76.

López De Lacey, A.M., Lopez-Caballero, A., Gomez-Estaca, M., Gomez-Guillen, J. \& Montero, M. (2012): Functionality of Lactobacillus acidophilus and Bifidobacterium bifidum incorporated to edible coatings and films. Innov. Food Sci. Emerg., 16, 277-282.

Maleki, G., Rostamian, M. \& Milani, J.M. (2014): Physical properties of gluten-free bread made of corn and chickpea flour. International J. Food Eng., 10, 467-472.

NAG, A., Han, K.S. \& SingH, H. (2011): Microencapsulation of probiotic bacteria using pH-induced gelation of sodium caseinate and gellan gum. Int. Dairy J., 21, 247-253. 
Pereira, J.O., Soares, J., Sousa, S., Madureira, A.R., Gomes, A. \& Pintado, M. (2016): Edible films as carrier for lactic acid bacteria. LWT - Food Sci. Technol, 73, 543-550.

Pourfarzad, A., Khodaparast, M.H., Karimi, M., Mortazavi, S.A., Ghiafeh Davoodi, M. \& Hematian Sourki, A. (2009): Effect of polyols on shelf-life and quality of flat bread fortified with soy flour. J. Food Process Eng., 34, 1435-1445.

Prasad, J., McJarrow, P. \& Gopal, P. (2003): Heat and osmotic stress responses of probiotic Lactobacillus rhamnosus HN001 (DR20) in relation to viability after drying. Appl. Environ. Microb., 69, 917-925.

QuezadA-Gallo, J.A. (2009): Delivery of food additives and antimicrobials using edible films and coatings. -in: Milda, E.E. \& Kerry, C.H. (Eds): Edible films and coatings for food applications. Springer Science + Business Media, New York. pp. 313-335.

Rhim, J.W., Gennadios, A., Weller, C.L., Cezeirat, C. \& Hanna, M.A. (1998): Soy protein isolate-dialdehyde starch films. Ind. Crops Prod., 8,195-203.

Rouhi, M., Razavi, S.H. \& Mousavi, S.M. (2017): Optimization of crosslinked poly (vinyl alcohol) nanocomposite films for mechanical properties. Mater. Sci. Eng. C., 71, 1052-1063.

Soukoulis, C., Behboudi-Jobbehdar, S., Macnaughtan, W., Parmenter, C. \& Fisk, I.D. (2017): Stability of Lactobacillus rhamnosus GG incorporated in edible films: Impact of anionic biopolymers and whey protein concentrate. Food Hydrocolloid., 70, 345-355.

Tripathi, M.K. \& GIRI, S.K. (2014): Probiotic functional foods: Survival of probiotics during processing and storage. J. Funct. Foods, 9, 225-241.

YANG, Y. (2008): Scientific substantiation of functional food health claims in China. J. Nutr., 138, 1199-1205.

Yoo, S. \& Krochta, J.M. (2012): Starch-methylcellulose-whey protein film properties. Int. J. Food Sci. Tech., 47, 255-261. 